Covered in: Web of Sciences (WOS); EBSCO; ERIH+; Google Scholar; Index Copernicus; Ideas RePeC; Econpapers; Socionet; CEEOL; Ulrich ProQuest; Cabell, Journalseek; Scipio; Philpapers; SHERPA/RoMEO repositories; KVK; WorldCat; CrossRef; CrossCheck

2018, Volume 10, Issue 1, pages: 155-170 | doi: https://doi.org/10.18662/rrem/26

\section{The Divine Proportion's Incidence in Facial and Dental Aesthetics}

\section{Oprea Valentin BUSU ${ }^{1} *$, Elena Cristina ANDREI ${ }^{2}$}

\author{
${ }^{1}$ Assistant, $\mathrm{PhD}$, University of \\ Craiova, Romania, \\ valentin busu@yahoo.com \\ Corresponding author \\ ${ }^{2}$ Student, University of Medicine \\ and Pharmacy of Craiova, Romania, \\ andreicristina2201@gmail.com
}

\begin{abstract}
As a science, facial and dental aesthetics is highly complex, the dentist being compelled to effectively exploit his abilities of reconstructing affected tissues, but also cultivate his aesthetic sense. Nowadays, dentists frequently face the patients high expectations, regarding dental structure and facial reconstruction. Most young patients tend to choose their model from the media, while patients over the age of 50 desire to have teeth like those of youth. It should also be noted that there is no concept of "cosmetic dentistry" as the teeth can only be adjusted in corellation to the face and body appearance. Thus, between physiognomy and the general appearance of the body and of the teeth a state of interdependence is in existence. One of the major errors that leads to endangering the quality of dental treatment and to patient dissatisfaction is the way in which the doctor-patient relationship is managed. If a person opts for an aesthetic treatment it is clear that it is facing a low self-esteem, in this case the dentist needing to address the disorder on two coordinates: an objective interpretation involves the sequencing of reconstructing a morphological and functional dentition and and establishing the issues related to patients notion of „beautiful”. At the same time, aesthetic dental treatment is based on the personality of the individual, the age, sex and patient's systemic diseases. The notion of "divine proportion” makes possible to perform „perfect” dental works that integrate the facial and somatic features, whose basic characteristics are symmetry, balance, continuity.
\end{abstract}

Keywords: aesthetics, self-esteem, reconstructing, proportionality, Divine Proportion.

How to cite: Busu, O.V., \& Andrei, E.C. (2018). The Divine Proportion's Incidence in Facial and Dental Aesthetics. Revista Romaneasca pentru Educatie Multidimensionala, 10(1), 155-170. https://doi.org/10.18662/rrem/26 


\section{Introduction}

The dental aesthetics is a creation of the 1960s. It first appears as a component of facial aesthetics (Daugaard-Jensen, 1957) and later it affirms a new discrete field of research (J. H. Lee, 1962), (Rickets, 1982). In the 1990s, dental aesthetics strengthen (Burden, 1995). Once self-esteem, dental aesthetics begins with a fruitful collaboration with the discipline from which it has separated (R. L. Lee, 2000). In the past two decades, we have witnessed an accelerated development of dental aesthetics enhanced by patients' aspirations towards beauty and the rapid evolution of technology (Klages, Bruckner, \& Zentner, 2004), (Ahmad, 2005), (Naini, 2011), (Levin, 2011). The latest research shows a research orientation and the psychological aspects of dental care. In the specialised literature there are concrete information about the realization of aesthetic dental treatment such as: measurements, angles, electronic systems for previewing the future appearance, systems used in collaboration with the laboratory of dental technique (digital fingerprint of the oral cavity, CAD / CAM). There are, also, many evasive information about issues such as the exposure of various artworks to understanding the phenomena of contrast, luminosity, shadows, symmetry (Demir, Oktay, \& Topcu, 2017; Yu, Cheng, Zhou, \& Cheng, 2017), (Moon \& Millar, 2017). Our study enters this new direction of investigation. This study emphasizes the importance of the fact that in the case of applying aesthetic treatment it is necessary to correlate the dentogingival aspect with two other aspects: the physiognomic (facial) and the somatic (corporal) appearance. If this criterion is not met, an adequate proportion cannot be obtained, and the treatment will be unsuccessful. Another important element highlighted in the article is that the dentist must have accurate knowledge about certain measurements that are being performed during aesthetic treatment, most doctors doing the work according to the visual method, which is not very accurate, but is guided more according to the dentist's experience and the way he perceives "beauty". Exact determinations prevent the occurrence of errors that may compromise the entire therapeutic act. Also, knowing how colors of a dental material intertwine, correct setting of symmetry, nuances and contrasts will be made after pre-studying works of art that clearly show these criteria. The saturation point must be known to the physician and understood by the patient: each patient has a certain saturation point of the tooth; when this point is reached then, any other stage of dental bleaching will be ineffective, producing only the demineralisation of the dental structure. 


\section{Aesthetics and the Divine Proportion}

This concept was first highlighted by Leonardo Da Vinci's masterpiece Mona Lisa, but was also approached by other artists such as Botticelli in his painting „Birth of Venus” or Georges Seurat in „A circus parade" (Huntley, 2012); (Dumitru, Budica, \& Motoi, 2016).

Mankind has shown interest in the dental and facial aesthetics since ancient times. Of course, each period has been marked by different stereotypes of „beauty” (Hook, Jonsson, Stahl, \& Mercurio, 2016). In ancient Egypt, there was a preference for people with bulky lips, tall forehead, elongated eye contour, and aquiline nose, such as Queen Nefertiti.

In ancient Greece, the facial beauty consists of the perfect equality of the three floors of the face and of the right profile. In ancient Rome, a great emphasis was placed on identifying facial features and correlating them with the individual's temperament and personality (Valceanu, 2004). During the Renaissance, the painter Leonardo Da Vinci imposed the concept of proportionality. For example, in his Mona Lisa masterpiece the divine proportion had as its starting point the construction of the ,golden rectangle", which requires the ratio of the sides to be equal to the number of gold $(1,618 \ldots)$. Another genius of the Renaissance era who imposed this trend of ,divine proportion” in art was Sandro Botticelli.

In the painting „Venus's Birth”, there is a harmony and balance in both the central element of the painting and the background, the divine proportion being emphasized by the geometric element of the triangle. There are two main triangles: one of them surrounds Venus's body, while the second triangle outlines the position of Venus's arms. This use of the proportion of gold is suggestive of the perfection, the ideal, the desire to embody the sublime, the absolute.

As far as the philosophers' involvement in aesthetics is concerned, some have been noticed over the years: Plato, whose interest was strictly about the notion of absolute beauty, without usefulness, but he neglectet the form. Then Artistoteles who was a promoter of the form, but did not consider the background (Frascari \& Ghirardini, 2015), (Vâlceanu, 2004).

Plato believed that "Beauty as a procreation goddess, it patronizes our own recreation of self in the image of divinity (Gilbert \& Kuhn, 1972)". Aristotle supports that the raw material of art begins to be organized when the reason combines these elements in certain proportions. In the middle Ages, reality's quantity and authenticity were considered proportionate with divinity's quantity and authenticity. The thinking of the years 1400-1700 reached major concepts, fundamental of esthetics and art's theory: beauty 
and grace, proportion and intentionality, nature and art, imitation and imagination, truth and plausibility (Tatarkiewicz, 1978).

The beauty, wherever it's found, is so appealing that it is recommended by itself, and it doesn't need apologies, but the art doesn't have such luck, it needs to justify itself, and the justification of the art has constituted, from the first reaction of Aristotle against Plato, the principal objective of esthetics.

Somaesthetics can be defined as a critical, ameliorating study of experience and of using the body as locus of esthetics sensory appreciation (aesthetics) and automatic modelation creativity. This strategy of somatic esthetics has ancient philosophical roots: Socrates, himself, announced the crucial role of the somatic preoccupation, ,he took care to train his body and he was kept well physically' (R. Shusterman, 2000; R. Shusterman, 2016). Horkheimer and Adorno bring a criticize to somatic esthetics that it is an instrument of publicity, used for obtaining measurable ostentatious results and for selling of countless goods, launching a billion-dollar cosmetics industry with all its specialized products for various parts of the body.

Somaesthetics claim that it targets body research, not only anthropological, sociological and historical, but also physiological and psychological. Moreover, through its practical dimension, somaesthetics engage in corporal practices that seem strange to the tradition of philosophy: fashion, cosmetics, body-building, and so on. The theory of psychic or esthetics distancing and its variants try to describe the esthetics experience more or less directly in the emotions terms that are triggers, and in function of the type of the objects that are generating these states. One of the things that we found about the perception with the help of psychology and modern philosophy is that the vision is governed by impressions. Perception does not only mean seeing, but seeing something like that. The esthetics perceptions perceive the object as an object itself, as it is perceives only its immediate appearance, such perception being sometimes described as impressionistic or imaginative (Townsend, 2000).

The gestalt psychology, based on a vast experimentation about the elements of beautiful form and the reasons for the man is attracting to it, claims that man likes the form because nature also likes the harmonious configuration, with its sub-characteristics of balance, rhythm, plan and hierarchical organization (R. Shusterman, 2000),(Voinea, Busu, Opran, \& Vladutescu, 2015; Voinea \& Negrea, 2017), (Sandu, 2017).

However, one of the most interesting views on the „beautiful” was given by I. Kant, in whose perception the judgment of beauty must be done in a disinterested way. Beginning with the nineteenth century, Victor Hugo 
introduced the idea that ,physical beauty is incomplete if it is not animated by spiritual beauty," revealing that body beauty does not achieve the ideal if it is not complete with the soul. In contemporary society, the notion of „aesthetic" and „beautiful” is extremely complex, requiring the inclusion of several elements such as physical, spiritual, but also efficiency (Busu \& Andrei, 2017).

\section{The Social Impact of Facial and Dental Aesthetics}

As far as the historical aspects of dentist facial aesthetics are concerned, we recall the Etruscans who used human teeth or teeth from animals (which were subject to finishing) that they inserted into the dental alveolus to mask the lack of one or more teeth. In case 2-5 teeth were missing, they used gold wire to strenghten the replacements.

The Mayans were the first to have complex teeth grinding, but also the first to make jade inlays, which had a strictly aesthetic role (R. Popescu, 2014). All these attempts to restore the normal and morphological appearance of the teeth had harmful effects, as it led to the installation of infections, periodontal inflammation or even necrosis (Faure, Rieffe, \& Maltha, 2002), (Cunningham \& Johal, 2015). Therefore, the purpose of aesthetic treatment is not only to restore the physical appearance, but also to provide optimal functionality. The foundations of modern dental-facial aesthetics were established in America around 1914, when in-depth studies on total prosthesis were conducted.

Symbolic interactionism is a concept of sociology that highlights the close link between the individual and the society in which he lives (Oprea \& Gavrilovici, 2015). In practice, a person is strongly influenced by the events and changes taking place in society, and therefore interdependence is created between the two components: individual-society.

Stănciulescu (Stanciulescu, 1996) is the one who makes a comparison, whose simplicity summarizes the interdependence mentioned above: „society and the individual are two faces of the same coin and cannot exist without each other." In the 21 st century, people are assaulted daily by a huge amount of information about current fashion, the way they should look, which led to the inability of many people to choose the correct option, as they are easily inflamed by what they hear and see. A target category is that of adolescents and young people who choose an idol from the media and tend to make aesthetic changes to resemble their idol.

A common example is that of stars who have promoted excess lip augmentation, dental bleaching and dental facials. Any patient who comes to 
the cabinet with the desire to do one of the treatments mentioned above is firmly convinced that they will suit their physiognomy. However, in many cases the doctor undermines their enthusiasm by saying it is not an appropriate treatment for them.

Any change produced, especially at the dental-facial level, is obligatory accompanied by measurements, setting of parameters and correlation with systemic affections, but also with the personality of the individual. Also, society shows its preference for people with a pleasant dental-faced look, which are considered more attractive, but also with a higher level of intelligence (Draghici, Preoteasa, Tancu, \& Preoteasa, 2015). Although the media is often criticized for promoting toxic patterns for society, we cannot overlook the beneficial role it brings by encouraging dental profiling.

In general, prophylactic dental treatment is promoted by advertising spots that support and encourage people to use toothpaste and mouthwash to prevent the risk of cavities or periodontal diseases, but also through health-related programs that address them and explained various symptoms of the oral cavity. Also, the media drew attention to the harmful effects of the amalgam fillings on the whole body (Valceanu, 2004).

Another important element in the social impact of aesthetics is the presence and formation of stereotypes (Popoviciu, 2013). Formation of stereotypes begins at an early age by observing and analyzing the multitudes of typologies of the individuals we encounter.

At the bottom of the stereotype is the social categorization, (Colhon, Vladutescu, \& Negrea, 2017), (Teodorescu, 2017). With this, people can be categorized (socially, economically, culturally). This concept is also reflected in dento-facial aesthetics by introducing individuals with a lined teeth, light color and proportionality of facial elements as people considered „beautiful”.

Another concept highlighted in dento-facial aesthetics is that promoted by Rosch (Rosch, 1973), which states that the „prototype” (in this case referring to the individual with a dental, facial and ideal somatic morphology) is represented by the qualities of the members of the society considered representative, and taken as a role model by a large part of the population (A. M. Popescu, 2015).

The reasons behind the patients' presence in the dental office are in most cases related to aesthetic reconstruction of the dental or facial structures.

At the same time, a patient who wants aesthetic treatment is a person with low self-esteem. Self-esteem is based on self-conception, self- 
confidence, self-love. An individual with low self-esteem is distinguished by: underestimating his/her qualities, frequent (sometimes unjustified) selfcriticism, neglect of physical appearance, avoiding social contact. Communication with such a patient must therefore be appropriate, trying to restore optimism and self-confidence, but also to provide the assurance of a good restoration.

Frequently, there are cases where the patient presents low selfesteem and anxiety about dental treatments. The behavior and reactions of this individual are very difficult to control, because there is a constant contradiction between the desire to regain aesthetic appearance and fear of treatment. Often, fear is manifested with a very high intensity which leads to abandoning treatment from an early stage. Therefore, during the first visit to the cabinet, the dentist should carefully observe the patient's behavior to determine if he or she is in contact with an anxious person.

The presence of anxiety can be determined by some indicators such as: redness of the skin with increased body temperature, excessive sweating, tachycardia, increased respiratory frequency, rigid posture, restlessness, agitation, nervous handling of objects (Collett, 2016).

A first step in starting the aesthetic dento-facial treatment is the achievement of informed anamnesis and informed consent. The patient's informed consent is of importance, being a legal act, by which the patient agrees to the treatments to be performed. If at the end of the sessions the patient changes his mind and is no longer satisfied with the treatment, the doctor cannot be accused of malpractice with this signed act. The basic prerequisite for the doctor not to be criminalized is that he / she respects the treatment steps, fails to perform the wrong maneuvers and uses appropriate materials (Nanu, 2012).

According to Freud, the anamnesis is an effective method of psychoanalysis. Anamnesis can be done by three methods: questionnaire, interview or mixed (contains both questionnaire and interview). It is advisable to use the mixed method, because it is the questionnaire that gives us the written evidence of the patient's presence in the dental office (Patroi, 2014). During the interview the emphasis will be on the content, the order and the iteration of the questions.

The dentist will begin the interview with questions about the patient's identity and familiarization questions for a better understanding of the social environment in which the patient lives, the place where he / she carries out his / her activities and his / her interactions with various people. Thus, from what the patient relates, the doctor will be able to form an idea of how he perceives life and how he sees „beautiful”. It is also 
recommended that closed questions be in a small number because they lead to the installation of monotony, while open-ended questions give fluency to expression (Dafinoiu, 2002), (Vladutescu, Budica, Dumitru, \& Stanescu, 2015). In the observation sheet, the physician will note the behavioral type, personality, and temperament of the patient for an effective adaptation of communication and interaction with the patient.

Communication in the dental office is one of the most important factors contributing to the success of the odonto-facial treatment. This is achieved by considering both the age of the patient and his personality.

In the case of teens and young people, who make the majority requests of aesthetic treatment, communication concerns two main aspects: confidentiality and acceptance of their opinion without criticism. Because they are in a state of confusion over their own identity (Pasca, 2006), it is important for the doctor to understand the reason that led them to make a change in their appearance(M. Frunza, Grad, \& Frunza, 2016), (S. Frunza, 2017).

Many of them will say that they want to have a similar image to their idol (singer, model, actor), but there is another category that wants to apply this treatment because of social pressures. In the latter case, there is a growing tendency among young people to criticize and blame certain colleagues / friends for their appearance, even leading to the phenomenon of bullying (especially in schools). In both situations, the physician is required to tell the patient whether the treatment chosen is appropriate or not, and what the consequences of inappropriate procedures can be. At the same time, young people presenting to the dentist with the desire to make some changes also exhibit a nonconformist or rebellious attitude (Pașca, 2006) which may have the most unexpected negative effects such as:

- excessive whitening of the teeth (within less than 6 months - one year) can reduce the enamel layer, exposing the dentine surfaces (yellowbrown dentine) leading to of dental sensitivity even to the weakest stimuli; irritations of gingival tissue;

- lip augmentation: not indicated for all physiognomies, may change the facial appearance in a negative way; once done, it takes a minimum of 6 months for the lips to return to their original size;

- application of dental faces: the natural tooth will be damaged (Manolea, 2013), more precisely it will be polished to create the space required for the face; the natural tooth will never have the shape, size, and initial resistance, the patient having to wear these facets throughout his life;

- wrinkle masking and correction of the naso-labial trench depth: these are strictly aesthetic treatments, but whose duration is conditioned by the patient's genetic potential, exposure to various harmful factors 
(prolonged exposure to sun dries the skin and accelerates wrinkle formation, improper hydration etc.), but also by the existence of certain systemic disorders: patients suffering from ulcer will always have the naso-labial dyke more pronounced.

There are situations where the doctor is confronted with patients who either do not know exactly what they want or have unrealistic expectations. To overcome this impediment, they make use of the „Digital Smile Design" app. This involves building a virtual model of the future restoration with a computer, a Power Point or Keynote software and a folder of patient photos(Lazarescu, 2013).

Thus, the patient will be able to preview how restoration affects their physical appearance and will decide more easily whether or not treatment is required. At the same time, this application streamlines the physician-patient relationship through the opportunity to ask for opinions, provide advice and clarify concerns.

After completing the thorough elaboration of the anamnesis, of the treatment plan with all its stages and establishing a good relationship between the doctor and the patient, it is possible to start the treatment. The basic principles of dento-facial aesthetics include: the notion of examination in facial aesthetics, smile aesthetics, dento-facial relations, dento-somatic relationships, gingival aesthetics and aesthetics of dental arches.

It is the examination of the facial area that highlights the concept of „divine proportion”. This implies: determining the presence or absence of facial symmetry, from the frontal norm with the help of the median line.

In general, people with facial symmetry are more readily accepted in society, are considered more attractive, while people with facial asymmetry are often distinguished leaders because they show ambition, perseverance, and are dominant.

Among the personalities with facial asymmetries we mention: Winston Churchill, Kim Jong-Il, King Henry VIII, Hitler. The patient's profile is normally studied from the lateral norm. The profile may exhibit concavity and convexity in some pathological conditions. The next measuring concerns the equality / inequality of the facets. According to the „divine proportion" it is ideal that the three regions: upper, middle and inferior are perfectly equal.

\subsection{Aesthetics of smile}

We all know that smile is a means of non-verbal communication through which we can externalize positive emotions, and we also know that the smile leads to highlighting the dental arches and highlights the contours 
of the lips. In aesthetic treatment, an important milestone is the smile line (Rindasu, 1998). This is the level at which the lip of the upper lip rises, also influencing the placement of the teeth. At the level of the front teeth, this positioning will obey the following rules: the central incisor package will be placed $1 \mathrm{~mm}$ above the lateral incisors, and the canine parcel will have a higher position than the central incisor parcel.

Ideally, the smile line is placed at the level of the teeth but there are many people who reveal a large portion of the gum, creating an unpleasant look. Also, during laughter, it has been observed that some individuals even discover the upper one, while most make the portion visible to the medial face of the upper two premolars.

\subsection{Dento-facial relationships}

Depending on the size of the faces, the patient can be classified as one of the following types: muscular, respiratory, cerebral or digestive (Deva, 2006). The muscular type has: a square face with the three equal facial floors, the respiratory type has an oval face and the middle floor is larger. The cerebral type has a trapezoidal face with a large base up and the upper floor prevailing. The digestive type has a trapezoidal face with a large base down, and the lower one is the most voluminous.

\subsection{Dento-somatic relations}

These relationships consider the height and weight of the patient. A patient with a medium or above average height will have slightly elongated and narrow teeth, while a shorter patient will have short and slightly wider teeth.

As far as gingival aesthetics are concerned, it is noted that male subjects have a more pronounced gum, while female flesh has a pale pink color. The aesthetics of the dental arcades, according to the „divine proportion" principle, states that the two arches have to be symmetrical, parallel to one another, and the upper arcade to circumscribe the lower arcade (R. Popescu, 2014).

An important place in dento-somato-facial aesthetics is the SAP (sex, age, personality) index introduced by Frush and Fisher (Lăzărescu, 2013). Thus, the following have been observed: teeth have a lighter color for young people and women and a darker color for men and the elderly.

At young people the incisal edge has a higher translucency, in the elderly the tooth is opaque; young people have a triangular interdentine papilla, and the adults and the elderly a rounded one. To create a rejuvenating effect, the aesthetic dental treatment involves visual access of 2$2.5 \mathrm{~mm}$ from the top front teeth. A rounded shape of the teeth is seen in women, and in males predominate sharp angles. 
Regarding the personality of the patient, it can be said that the canine morphology betrays the personality, namely a canine with the tip of the strong cusp indicates a strong, ambitious person, eager to assert and to take a high position in society, while individuals with a flattened cuspid suggest gentleness, sincerity, devotion, and are often involved in humanitarian projects.

The materials used are: acrylic, ceramic (porcelain) and most recently zirconium. Acrylic is aesthetic, it is at a low price, but it has two disadvantages: it wears out and can induce allergic reactions. Ceramic has excellent biocompatibility, superior aesthetics, translucency, color is maintained over time, but has the disadvantage of being brittle (Manolea, 2011).

Currently, zirconium has become a preferred material for more doctors and patients due to its qualities: high hardness, very good mechanical strength, $99.9 \%$ purity, biocompatibility, aesthetics, thermoinsulating, corrosion resistance. Zirconia is besides a physiognomic material and a material that integrates well from the functional point of view in the dento-maxillary apparatus.

\section{Psychological Integration of Foreign Bodies into The Oral Cavity}

According to Montaigne, „beauty is an excellent recommendation” (R. Shusterman, 2000) a statement whose connotation can be fully exemplified in the dental-facial aesthetic treatments. The prevailing emphasis in todays society is on the physical component, often neglecting the functional-organic and psychological component. Patients using dental aesthetic treatments undergo pre-prosthetic and prosthetic maneuvers .

If pre-prosthetic maneuvers require a biological dental tissue sacrifice (R. Popescu, 2014), the prosthetic ones are characterized by inserting a foreign body into the remaining tissue. This situation involving the introduction of foreign bodies into the oral cavity leads to imbalances and psychological disorders. Recently, it has been observed that patients with extensive prosthetic works tend to see themselves as „handicapped” and associate dental prosthesis with another type of prosthesis (arm, leg etc.)

Even though a prosthetic work can be regarded as a minimally invasive minor treatment, for the patient is of great significance, some individuals even developing psychoses and psychological rejection of the applied treatment. The most difficult are patients who, on the one hand, want the dental reconstruction in order to preserve their appearance, and on the other hand they do not mentally support the idea of having to wear a 
foreign body permanently. Among the most frequent mental disorders we can recall behavioral disorders manifested by increased nervousness, irritability, sometimes even aggressive manifestations.

After the onset of behavioral disorders some somatic disorders may manifest themselves, such as increased blood pressure and pulse (tachycardia), dyspnea, chronic fatigue, respiratory disturbance manifested by heavy breathing, digestive disorders. At the same time, neurotic disorders such as: neurosis, tics disease and of crying spasms can also be noticed. One aspect that is not to be neglected is the neurotic personality disorder or obsessive-compulsive disorder, when the patient exaggerates the details, becomes inflexible, hardly accepting any opinions or advice from others. Another condition is the anxiety disorder present when the patient is in a constant state of fear, of inferiority, having a lot of worries about how he is perceived by society. They also fear criticism from other people, have a continual feeling that they are rejected by other members of the community.

According to P. Pichot (Pichot, 1987), „Anxiety is an emotional state based on three fundamental elements: perceiving an imminent danger, an attitude of waiting this danger and a sense of disorganization related to the consciousness of total impotence in the face of this danger". That is why the dentist is obliged to be an excellent psychologist because the patient who wants to improve or correct his physical appearance has probably a fragile psychic. Thus, by properly addressing the clinical case by providing information on the advantages, disadvantages and consequences that may occur during both therapy and post-surgery, anxiety is avoided.

The addiction disorder can occur in the relationship between the dentist and the patient, because prosthetic aesthetic interventions can stretch over a long period of time (from two weeks to two months). Thus, by frequent visits to the dental office and by strengthening the relationship between the doctor and the patient, it may be that the odonto-periodontal therapeutical act creates a state of dependence of the patient towards his physician. The patient will be unsure of the decisions he has to take and can even get to the point of installing the fear of abandonment.

A special category of patients are those who want the restoration of dental structures altered over time or due to the appearance of traumatic injuries, but on the condition that they maintain their dento-maxillary abnormalities in the future prosthetic work. The most common dental abnormalities they desire to maintain are diastem, dental incongruity and oro- or vestibulo-position (Manolea, 2013). Although in an initial phase it may seem absurd that an individual wants to translate defects into a prosthetic piece that can embody perfection, it has a psychological 
foundation: the person is pleased with his appearance and believes that by removing these "defects" he will no longer be the same person (Grabara \& Kot, 2017), (Siminica, Motoi, \& Dumitru, 2017), (Pacana \& Ulewicz, 2017). The issue of diastere has been a topic debated intensely by dentists because there are situations in which the patient wants to mask diastema, but this can not be possible because it can cause speech disturbances, but there are also situations in which the doctor rebuilds the structure of the two incisors without removing the diastema, due to the patient's conception that it would be an element of modernity, taking the model of the pop singer Madonna.

\section{Romanian Professional Training}

The specifics of the professional training of the Romanian dentists, in the context of the use of the divine proportion in the dental practice, consists in attending a compulsory course titled „Dental-facial aesthetic course"; this is accredited by the College of dentists in Romania (theoretical part and practical part). The information obtained during this course is in accordance with the Advanced Graduate Program in Prosthodontics from Harvard University - School of Dental Medicine.

\section{Conclusion}

In conclusion, it can be said that the present society places great importance on the aesthetic dento-somato-facial aspect, which has led to the increase in demand for modelling / cosmetic and aesthetic treatments. This situation has been perceived by dentists as a real challenge, encouraging them to participate in new medical education courses to learn and adapt to the current demands of society in terms of reconstruction and aesthetic modeling.

\section{References}

Ahmad, I. (2005). Anterior dental aesthetics: dental perspective. British dental journal, 199(3), 135.

Burden, D. J. (1995). The ranking of dental aesthetics. . British journal of orthodontics, 22(3), 259-261.

Busu, O. V., \& Andrei, E. C. (2017). Managing a Dental Practice and How to Deal with the Patient's Emotions. Logos Universality Mentality Education Novelty, Section: Social Sciences, 6(1), 109-116 
Colhon, M., Vladutescu, S., \& Negrea, X. (2017). How Objective a Neutral Word Is? A Neutrosophic Approach for the Objectivity Degrees of Neutral Words. Symmetry, $9(280)$.

Collett, P. (2016). How to Tell what People are Thinking. . New York: HarperCollins.

Cunningham, S. J., \& Johal, A. (2015). Orthognathic correction of dentofacial discrepancies. . British dental journal, 218(3), 167.

Dafinoiu, I. (2002). Personalitatea. Metode calitative de abordare. Observatia si interviul. Iasi: Polirom.

Daugaard-Jensen, I. (1957). Orthodontics and Facial Aesthetics. European Ortodontic Society(33).

Demir, F., Oktay, E. A., \& Topcu, F. T. (2017). Smile and dental aesthetics: a literature review Medical Sciences, 6, 172-177.

Deva, V. (2006). Elemente de morfologie functionala a sistemului stomatognat. Craiova: Sitech.

Draghici, R., Preoteasa, C. T., Tancu, A. M. C., \& Preoteasa, E. (2015). Impactul antrenamentului determinarii culorii dintilor asupra perceptiei esteticii dentare. Romanian Journal of Stomatology, 61(3), 238242.

Dumitru, A., Budica, A. B., \& Motoi, A. G. (2016). Managerial-systemic profile of a tourism company. Polish Journal of Management Studies, 13(2), 36-45.

Faure, J. C., Rieffe, C., \& Maltha, J. C. (2002). The influence of different facial components on facial aesthetics. The European Journal of Orthodontics, 24(1), 1-7

Frascari, M., \& Ghirardini, L. G. V. (2015). Contra divinam proportionem. . Birkhauser, Cham, 619-626.

Frunza, M., Grad, I., \& Frunza, S. (2016). Aspects ethiques des stereotypes de genre dans les publicites roumaines. Essachess-Journal for Communication Studies, 9(1), 143-158.

Frunza, S. (2017). Seeking Meaning, Living Authenticity and Leadership in Public Space. A Philosophical Perspective. Transylvanian Review of Administrative Sciences, 13(52), 23-37.

Gilbert, K. E., \& Kuhn, H. (1972). Istoria esteticii. Bucuresti: Editura Meridiane

Grabara, J., \& Kot, S. (2017). Business Relations in Reverse Logistics Outsourcing. . Economic Analysis, 43(1-2), 99-107.

Hook, K., Jonsson, M. P., Stahl, A., \& Mercurio, J. (2016). Somaesthetic appreciation design. Proceedings of the 2016 CHI Conference on Human Factors in Computing Systems., 3131-3142. 
Huntley, H. E. (2012). The divine proportion. Courier Corporation Klages, U., Bruckner, A., \& Zentner, A. (2004). Dental aesthetics, selfawareness, and oral health-related quality of life in young adults. The European Journal of Orthodontics, 26(5), 507-514.

Lazarescu, F. (2013). Incursiune in Estetica Dentara. Bucuresti: SSER.

Lee, J. H. (1962). Dental aesthetics. Wright, Bristol.

Lee, R. L. (2000). Standardized head position and reference planes for dento-facial aesthetics. Dentistry today, 19(2), 82-87.

Levin, E. I. (2011). The updated application of the golden proportion to dental aesthetics. . Aesthetic dentistry today, 5(3), 22-27.

Manolea, H. (2011). Materiale Dentare. Craiova: Sitech.

Moon, R. J., \& Millar, B. J. (2017). Dental Aesthetics: A Study Comparing Patients' Own Opinions with Those of Dentists. . Open Journal of Stomatology, 7(4), 225.

Naini, F. B. (2011). Facial aesthetics: concepts and clinical diagnosis. . New Jersey, United States: John Wiley \& Sons.

Nanu, A. (2012). Malpraxisul medical. 7 Instrucțiuni de siguranta. Suceava: Tipolidana.

Oprea, L., \& Gavrilovici, C. (2015). Bazele comportamentului individual in sanatate. . Bucuresti: PRO Universitaria.

Pacana, A., \& Ulewicz, R. (2017). Research of determinants motiving to implement the environmental management system. Polish Journal of Management Studies, 16(1), 165-174

Pasca, D. M. (2006). Noi perspective in psihologia medicala. Targu Mures: Editura Ardealul.

Patroi, G. (2014). [Curs Diagnostic Oro-Dentar.].

Pichot, P. (1987). L'anxiete. . Paris: Masson

Popescu, A. M. (2015). Prescriptive Models of Intervention Strategy Choice of Manager in the Resolution of Conflict Moods. Procedia Social and Behavioral Sciences, 197-202.

Popescu, R. (2014). Ocluzologie dentara. Craiova: Editura Medicala Universitara.

Popoviciu, S. (2013). Psibologie socială. O abordare contextuală a individului ca actor social. . Oradea: Editura Emanuel University.

Rickets, R. M. (1982). Divine proportion in facial aesthetics. Clin Plast Surg, 9(4), 401-422.

Rindasu, I. (1998). Proteze dentare. Bucuresti: Editura Medicala.

Rosch, E. H. (1973). Natural categories. Cognitive psychology, 4(3), 328-350. 
Sandu, A. (2017). The Development of Human Resources Romanian Journal for Multidimensional Education/Revista Romaneasca pentru Educatie Multidimensionala, A Qualitative Analysis(9), 2.

Shusterman, R. (2000). Living beauty, rethinking In Pragmatist aesthetics. Lanham, Maryland, United States: Rowman \& Littlefield Publishers.

Shusterman, R. (2016). Pragmatism and the philosophical life. In Practicing philosophy. Routledge

Siminica, M., Motoi, A. G., \& Dumitru, A. (2017). Financial management as component of tactical management. Polish Journal of Management Studies, 16(1), 206-217.

Stanciulescu, E. (1996). Teorii sociologice ale educatiei. Iasi: Polirom.

Tatarkiewicz, W. (1978). Istoria esteticii. Bucuresti: Editura Meridiane.

Teodorescu, B. (2017). The communication between the media and tradition. Social Sciences and Education Research Review, 4(2).

Townsend, D. (2000). Introducere în estetica. Bucuresti ALL Educational.

Valceanu, A. (2004). Estetica în Medicina Dentara. Timisoara: Editura Brumar. Vladutescu, S., Budica, I., Dumitru, A., \& Stanescu, G. C. (2015). Functions and forms of managerial communication. Polish Journal of Management Studies, 12(2), 191-201

Voinea, D. V., Busu, O. V., Opran, E. R., \& Vladutescu, S. (2015). Embarrassments in managerial communication. Polish Journal of Management Studies, 11(2), 171-180.

Voinea, D. V., \& Negrea, X. (2017). Journalism, Between an Avant-Garde Profession and a Profession in Crisis. Social Sciences and Education Research Review, 4(1), 191-199.

Yu, H., Cheng, S. L., Zhou, J. Y., \& Cheng, H. (2017). A survey on general knowledge and influencing factors of dental aesthetics among three universities students in Fuzhou city Shanghai journal of stomatology, 26(5), 510-515 